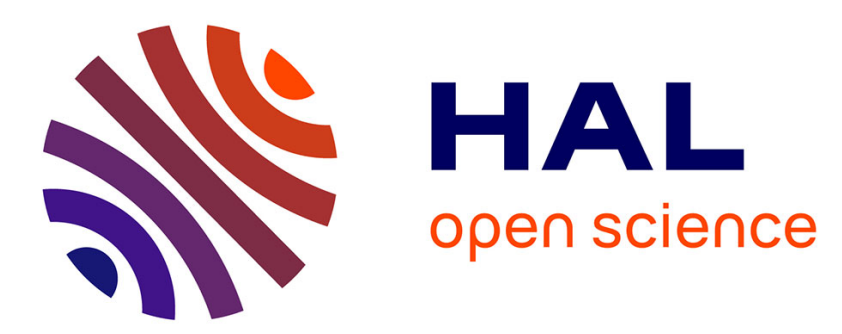

\title{
Early stages of precipitation and microstructure control in Mg-Rare Earth alloys
}

Caroline Antion, Patricia Donnadieu, Catherine Tassin, Alexander Pisch

\section{To cite this version:}

Caroline Antion, Patricia Donnadieu, Catherine Tassin, Alexander Pisch. Early stages of precipitation and microstructure control in Mg-Rare Earth alloys. Philosophical Magazine, 2006, 86 (19), pp.27972810. 10.1080/14786430600557193 . hal-00513656

\section{HAL Id: hal-00513656 https://hal.science/hal-00513656}

Submitted on 1 Sep 2010

HAL is a multi-disciplinary open access archive for the deposit and dissemination of scientific research documents, whether they are published or not. The documents may come from teaching and research institutions in France or abroad, or from public or private research centers.
L'archive ouverte pluridisciplinaire HAL, est destinée au dépôt et à la diffusion de documents scientifiques de niveau recherche, publiés ou non, émanant des établissements d'enseignement et de recherche français ou étrangers, des laboratoires publics ou privés. 


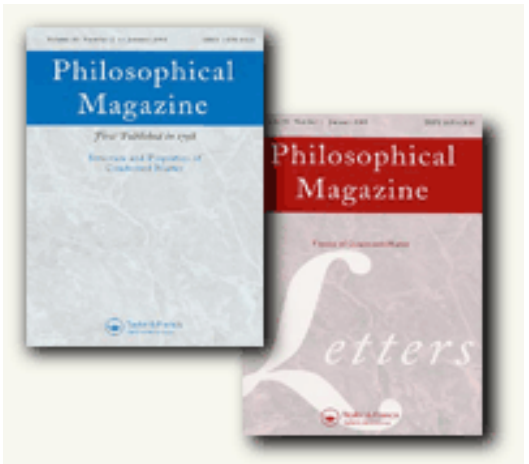

\section{Early stages of precipitation and microstructure control in Mg-Rare Earth alloys}

\begin{tabular}{|c|c|}
\hline Journal: & Philosophical Magazine \& Philosophical Magazine Letters \\
\hline Manuscript ID: & TPHM-05-Oct-0460.R1 \\
\hline Journal Selection: & Philosophical Magazine \\
\hline $\begin{array}{r}\text { Date Submitted by the } \\
\text { Author: }\end{array}$ & 22-Dec-2005 \\
\hline Complete List of Authors: & $\begin{array}{l}\text { ANTION, Caroline; LIMA, ESIA } \\
\text { Donnadieu, Patricia; LTPCM- umr 5614, INPG-CNRS } \\
\text { TASSIN, Catherine; LTPCM-umr5614, INPG-CNRS } \\
\text { PISCH, Alexander; LTPCM-umr5614, INPG-CNRS }\end{array}$ \\
\hline Keywords: & $\begin{array}{l}\text { transmission electron microscopy, age-hardening, Mg alloys, } \\
\text { precipitation }\end{array}$ \\
\hline Keywords (user supplied): & \\
\hline
\end{tabular}

\section{S ScholaroNE \\ Manuscript Central}




\section{Early stages of precipitation and microstructure control in Mg-Rare Earth alloys C.Antion ${ }^{1}$, P.Donnadieu ${ }^{2}$, C.Tassin ${ }^{2}$ and A.Pisch ${ }^{2}$}

'Laboratoire d'Instrumentation et de Matériaux d'Annecy, ESIA, Domaine Universitaire, BP806, 74016 Annecy cedex, France

${ }^{2}$ Laboratoire de Thermodynamique et de Physico-Chimie Métallurgiques, Domaine Universitaire, 1130 rue de la piscine, F-38402 Saint Martin d'Hères cedex, France

\begin{abstract}
Hardening precipitation frequently occurs in Mg-Rare Earth (RE) alloys after heat treatment in the $150^{\circ} \mathrm{C}-200^{\circ} \mathrm{C}$ range. Early stages of precipitation have been studied in detail by transmission electron microscopy in two Mg-RE alloys (Mg-Y-Gd and $\mathrm{Mg}-\mathrm{Y}-\mathrm{Nd}$ ). Two types of structures may be involved in the precipitation sequence: a $\mathrm{DO}_{19}$ phase and the so-called orthorhombic $\beta$ ' phase. The structural relationship between $\mathrm{DO}_{19}$ and $\beta$ ' phases has been established in underaged and overaged states from the observations at peak ageing. We show that the earliest precipitates play a key role in the selection of phases developing in overaged states. Depending on the habit plane of the precipitates present in the early states, either the $\mathrm{DO}_{19}$ or the $\beta$ ' phase will grow in further ageing. The Mg-Y-Gd and Mg-Y-Nd alloys illustrate the different microstructures resulting from such selection. Due to the selective growth of the $\beta$ ' phase, the Mg-Y-Gd alloys are characterized by a fine scale microstructure which provides improved mechanical properties.
\end{abstract}

\title{
1. Introduction
}

Early stages of precipitation in alloys frequently result in planar precipitates. The latter. form due to the tendency of alloying elements to chemical ordering combined with local

| deformation and interfacial energy effects. In light alloys, the early precipitation states are usually responsible for hardening and often stand as precursors for other phases which can form later during ageing. In the classical $\mathrm{Al}-4 \% \mathrm{Cu}$ alloys and also several other $\mathrm{Al}$ alloys, the sequences from the Guinier-Preston zones to overaged precipitation states have been established and widely studied [1,2]. Among magnesium alloys, the Mg-Rare Earth (RE) alloys are also known for their precipitation hardening [3]. Mg-RE alloys are attractive candidates for structural applications such as transport industries because of their low density combined with mechanical properties like a significant hardening for short ageing time and a high creep resistance at $250^{\circ} \mathrm{C}$. For example, the $\mathrm{Mg}$-Y-Nd system is the base for the commercial WE series alloys [4]. Besides, some recent studies [5,6,7] have pointed out the interest of the $\mathrm{Mg}$-Y-Gd system. However, the precipitation microstructure in Mg-alloys is much less documented than in $\mathrm{Al}$ alloys. In particular the earliest stages have been rarely studied though, as shown in the present work, they may have a strong influence on the microstructure at peak ageing as well as at longer ageing times. 
In Mg-RE alloys, similar precipitation sequences are reported in the temperature range from ambient to $400^{\circ} \mathrm{C}[3,7,8,9]$. The magnesium supersaturated solid solutions $(\mathrm{Mg})_{\mathrm{sss}}$ in binary or more complex $\mathrm{Mg}$ - RE alloys decomposes in the following way [3]:

$$
(\mathrm{Mg})_{\mathrm{sss}} \rightarrow \beta^{\prime},\left(\mathrm{DO}_{19} \text { phase }\right) \rightarrow \beta^{\prime}(\text { bco phase }) \rightarrow \beta \text { (cubic type) }
$$

In $\mathrm{Mg}$ alloys aged at low temperature, a most common feature is to form hexagonal ordered structure [3], namely a $\mathrm{DO}_{19}$ structure, which organises as a coherent ordered phase in the magnesium lattice. The $\mathrm{DO}_{19}$ phase (usually called $\beta$ "' in $\mathrm{Mg}$ alloys) has a $\mathrm{Mg}_{3} \mathrm{X}$ composition with cell parameters of $\mathrm{a}_{\mathrm{DO} 19}=2 \mathrm{a}_{\mathrm{Mg}}=0.642 \mathrm{~nm}, \mathrm{c}_{\mathrm{DO} 19}=\mathrm{c}_{\mathrm{Mg}}=0.521 \mathrm{~nm}$ [3]. The $\beta$ ' phase is usually described by a based-centred or a body-centred orthorhombic (bco) structure $[3,10,11,12]$. The bco structure is also coherent with the $\mathrm{Mg}$ matrix $\left(\mathrm{a}_{\mathrm{bco}}=2 \mathrm{a}_{\mathrm{Mg}}=0.642 \mathrm{~nm}\right.$, $\mathrm{b}_{\mathrm{bco}}=4 \sqrt{3} \mathrm{a}_{\mathrm{Mg}}=2.223 \mathrm{~nm}, \mathrm{c}_{\mathrm{bco}}=\mathrm{c}_{\mathrm{Mg}}=0.521 \mathrm{~nm}$ ) [3]. According to the structure and cell parameters, $\mathrm{DO}_{19}-\beta^{\prime}$, and bco- $\beta$ ' phases have a strong structural relationship with the matrix. In the course of TEM investigations on some commercial WE series alloys, the $\beta$ ' phase composition has been determined by EDX to be close to $\mathrm{Mg}_{12} \mathrm{YNd}$ and $\mathrm{Mg}_{12} \mathrm{YNd}_{2}$ $[9,13]$.

The present study will focus on the early stages of precipitation in Mg-Y-Nd and MgY-Gd alloys as well as the microstructure in the overaged state. The $\mathrm{Mg}-\mathrm{Y}-\mathrm{Nd}$ alloy studied here corresponds to a WE43 alloy, whose composition is Mg-3.97 wt.\%Y-2.30 wt.\% Nd- 0.4 wt.\% $\mathrm{Zr}(1.14$ at $\% \mathrm{Y}-0.41$ at $\% \mathrm{Nd})$; in the following, this alloy is referred as the $\mathrm{Mg}-\mathrm{Y}-\mathrm{Nd}$ alloy. The Mg-Y-Gd system is here illustrated by two alloys : namely a Mg-1 wt $\% \mathrm{Mn}-3$ wt $\%$ Y- 8 wt $\%$ Gd (0.9 at $\%$ Y- 1.3 at $\%$ Gd) alloy and a Mg- 1 wt $\%$ Mn- 5 wt $\%$ Y- 4 wt $\%$ Gd (1.4 at\% $\mathrm{Y}-0.6$ at\%Gd) alloys. The $\mathrm{Zr}$ addition in $\mathrm{Mg}-\mathrm{Y}-\mathrm{Nd}$ alloys contributes to grain refinement while $\mathrm{Mn}$ is added in $\mathrm{Mg}-\mathrm{Y}-\mathrm{Gd}$ alloys to improve the corrosion resistance. Neither $\mathrm{Mn}$ nor $\mathrm{Zr}$ additions play a part in the precipitation microstructure of interest here. The two $\mathrm{Mg}-\mathrm{Y}-\mathrm{Gd}$ alloys essentially differ by their $\mathrm{Gd} / \mathrm{Y}$ ratio. As no significant difference in the microstructure has been observed, these alloys will be only referred to as the Mg-Y-Gd alloy regardless of the Y/Gd ratio. The main technique used for identification of phases and of their structural relationships is High Resolution Transmission Electron microscopy (HRTEM) due to the very fine scale of the microstructure,

\section{Material and methods}

The Mg-Y-Nd alloys - here WE43 alloys purchased in as cast conditions from the Magnesium Elektron Company [4] - were solution treated at $525^{\circ} \mathrm{C}$ for 8 hours and quenched before ageing at $150^{\circ} \mathrm{C}$ and $250^{\circ}$ for times ranging from $864 \mathrm{~h}$ to $1896 \mathrm{~h}$ and $1 \mathrm{~h}$ to $16 \mathrm{~h}$,

| respectively. To prevent the samples from oxidation during solution treatments, they were put in a pure iron tube and sealed into a quartz tube under an argon atmosphere. Solution treatments were carried out in a muffle furnace and the samples were quenched by breaking the quartz tube in water. Further ageing is carried out in a furnace under air and samples are quenched in water.
Deleted: an

Deleted: ; its

Deleted: are

Deleted: emphasize

Deleted: first
Deleted:

Deleted: microstructure being on a very fine scale,

Deleted: has been here the

Deleted: main technique for

identification of phases and of their structural relationships 
The Mg-Y-Gd alloys were made by levitation melting in cold copper crucibles using pure components. The main impurities in magnesium were $\mathrm{Al} 0.02 \mathrm{wt} \%, \mathrm{Fe} 0.04 \mathrm{wt} \%, \mathrm{Mn}$ $0.05 \mathrm{wt} \%$, others below $0.01 \mathrm{wt} \%$. According to emission spectrography analysis the impurities content in Yttrium was Ds $100 \mathrm{ppm}, \mathrm{Gd} 30 \mathrm{ppm}$, Yt 7ppm. In Gadalonium, no Rare Earth impurities were below the detection level. Master alloys containing RE elements, manganese and a small amount of magnesium were first melted in a cold copper crucible furnace,

After several melts, $\underline{5 \text { gram balls of master alloys were formed which were then }}$ remelted with the magnesium balance to reach the desired nominal composition. At least 4 or 5 melts were necessary to mix the master alloy and magnesium. In the final step, the melt is cast in a steel crucible leading to cylindrical ingots of $15 \mathrm{~mm}$ diameter and $100 \mathrm{~mm}$ long. Nominal alloy compositions have been further measured by Inductively Coupled PlasmaAtomic Emission Spectroscopy (ICP-AES). The Mg-Y-Gd alloys in as cast conditions were solution treated at respectively $525^{\circ} \mathrm{C}$ and $480^{\circ} \mathrm{C}$ for $8 \mathrm{~h}$ in a quartz sealed tube under an argon atmosphere, and then quenched into water. Further ageing treatments were then carried out under air at $200^{\circ} \mathrm{C}$ and $250^{\circ} \mathrm{C}$ for times ranging from $1 \mathrm{~h}$ to $1104 \mathrm{~h}$.

Specimens for Transmission Electron Microscopy (TEM) were obtained by mechanical polishing up to $40 \mu \mathrm{m}$ thickness; the $3 \mathrm{~mm}$ discs were made either by ultrasonic cutting or by punching. They were ion milled using the Precision Ion Polishing System (GATAN 691) operating first at $4 \mathrm{kV}$ accelerating voltage and $10^{\circ}$ angle to polish the surface until perforation and then at $2 \mathrm{kV}$ accelerating voltage and $2^{\circ}$ angle to remove surface damage. Microstructural examination was carried out on a JEOL 3010 microscope operating at $300 \mathrm{kV}$; the microscope point resolution was $0.25 \mathrm{~nm}$. As precipitation occurs in the magnesium prismatic planes, observations can be limited to the [0001] and [11-20] zone axes.

As precipitate/matrix coherency is a strong feature of earliest stages, the HRTEM images were further studied with a specific image analysis, the so-called geometric phase method [14]. This method allows quantitative information like the displacement field of the matrix in the vicinity of precipitates to be derived from $\overline{H R T E M}$ images. It is worth noting that this method is very sensitive and is able to detect displacement field even when not detectable by eye inspection of HRTEM prints. Of course, it works essentially for microstructures | associated with negligible displacement along the zone axis direction. The phase image method can be summarized as follows. The HRTEM image of a crystalline area can be decomposed in a set of periodic components $\mathrm{g}_{\mathrm{i}}$. In a perfect lattice, the phase of each $\mathrm{g}_{\mathrm{i}}$ component is constant, while in a lattice distorted by a displacement field $\mathrm{u}(\mathrm{x}, \mathrm{y})$, the phase is $2 \pi \mathrm{g}_{\mathrm{i}} \mathrm{u}(\mathrm{x}, \mathrm{y})$. This property is a direct result of image formation in HRTEM. Hence, on the phase map calculated from the HRTEM image, in each point $(x, y)$, the image intensity is proportional to the displacement $\mathrm{u}_{\mathrm{i}}(\mathrm{x}, \mathrm{y})$. The scaling factor is simple: the image grey level full range corresponds to a fringe spacing $\left(1 /\left|\mathrm{g}_{\mathrm{i}}\right|\right)$.

\section{TEM investigations of the nanoscaled microstructure}

For both Mg-Y-Gd and Mg-Y-Nd alloys, ageing heat treatments appropriate for a comparative study have been determined from hardness measurements. Figure 1 shows the hardness behaviour for the different alloy compositions that has allowed to determine the
Deleted:

Deleted: consist in about 5 grams balls. Later, they were

Deleted: to derive from HRTEM images

Deleted: deformation

Deleted: to

Deleted: deformation 
aging treatment. The following states were selected for detailed microstructural investigation: peak hardening, underaged and overaged stages.

\subsection{Chemical ordering in the early precipitation states}

Figure $2 \mathrm{a}$ gives the diffraction patterns along the $[0001]_{\mathrm{Mg}}$ zone axis in the Mg-Y-Gd alloy aged $4 \mathrm{~h}$ at $200^{\circ} \mathrm{C}$. On long exposed negatives, one can detect very diffuse intensity centred on positions expected for a $\mathrm{DO}_{19}$ ordering on the $\mathrm{Mg}$ lattice. The diffraction pattern along the [11-20] zone axis is not shown here as even on long exposed negatives diffuse features were hardly noticed. According to the HRTEM image (Fig. 2b), no clear feature appears except some local contrast, which may be due to some very local ordering. Consistently with the diffraction pattern (Fig,2a), Fast Fourier Transform (FFT) carried out on Figure $2 \mathrm{~b}$ also shows very diffuse intensity at $\mathrm{DO}_{19}$ expected positions. To further localize the $\mathrm{DO}_{19}$ ordered regions, numerical annular dark field images were made using a ring selection as shown on the FFT in Figure 2c. The numerical DF in Figure $2 \mathrm{~d}$ points out higher intensity regions but it is difficult to conclude on their morphology, the domain being too small in

| comparison to the $\mathrm{DO}_{19}$ cell size.

In Mg-Y-Nd alloy aged $864 \mathrm{~h}$ at $150^{\circ} \mathrm{C}$, the diffraction patterns (Fig.3a, b) show diffuse streaks centred on positions consistent with a $\mathrm{DO}_{19}$ ordering in the $\mathrm{Mg}$ matrix. Since the streaks on the [11-20] diffraction pattern are elongated in the basal $\mathrm{Mg}$ plane and narrow in the [0001] direction, the corresponding features in direct space are expected to be platelets developed along the [0001] direction. Usually, on fine scale precipitates, the precipitate length along the $\mathrm{Mg}$ c-axis is difficult to determine because precipitates are embedded in the matrix and seen only edge on. However, the c-axis dimension can be derived from the diffraction | pattern like that of the [11-20] zone axis since the streak dimension parallel to the $c$ axis scales as $1 / \mathrm{L}$ where $\mathrm{L}$ is the precipitate length along the c-axis. From the streak intensity profile, we estimate to $8 \mathrm{~nm}$ approximately the precipitate length along the $\mathrm{Mg}$ c-axis. To localize the region presenting $\mathrm{DO}_{19}$ ordering, annular numerical dark field imaging has been also carried out on Figure $3 \mathrm{c}$. The numerical dark field image (Fig. $3 \mathrm{~d}$ ) associated with close examination of the HREM starting image (Fig. 3c) indicates two types of very fine precipitates. They consist of more or less planar features; some of them are marked by arrows in Figure $3 \mathrm{~d}$, The first type is made of monoplanar precipitates laying in the (1-100) $\mathrm{Mg}$ plane while the second type is rather located in a $(11-20) \mathrm{Mg}$ plane. In both cases, one can recognise the local $\mathrm{DO}_{19}$ order which is also confirmed by the high intensity of these regions in the numerical dark field image.

\subsection{Displacement field in the vicinity of the earliest precipitates}

Since the earliest precipitates form coherently in the $\mathrm{Mg}$ matrix while involving atoms of quite different sizes, special interest was paid to the local deformation of the magnesium matrix in the precipitate vicinity. Hence, HRTEM images have been further analysed using | the phase image method [14] to examine whether the precipitates were associated with
Deleted: pre-peak

Deleted: first

Deleted: 1

Deleted: $1 b$

Deleted: $1 \mathrm{a}$

Deleted: $1 \mathrm{~b}$

Deleted: $1 \mathrm{c}$

Deleted: 1d

Deleted: of

Deleted: 2

Deleted: one

Deleted: $2 \mathrm{c}$

Deleted: $2 \mathrm{~d}$

Deleted: to

Deleted: $2 \mathrm{c}$

Deleted: in

Deleted: 2

Deleted: c

Deleted: consists in

Deleted: Deformation 
specific displacement field. The image analysis has been here carried out on the Mg-Y-Nd alloys because the precipitate HRTEM images were of better quality than in the Mg-Y-Gd alloys.

Figure $4 \mathrm{a}$ shows one precipitate elongated along the (11-20) plane for which the geometric phase analysis has been applied. The phase map in Figure $4 \mathrm{~b}$ has been derived for the (11-20) selected vector. Hence the phase image gives here the displacement of $(11-20)$ planes. According to the profile (Fig. $4 \mathrm{~d}$ ) taken across the precipitate, the phase fluctuation along the [11-20] direction remains quite small. For a (11-20) vector, a $2 \pi$ radian phase or 256 grey levels on the image corresponds to the spacing $0.16 \mathrm{~nm}$. The phase fluctuations in Figure $4 \mathrm{~b}$ are then associated with displacement of approximately $\pm 0.003 \mathrm{~nm}$. The phase varies quite irregularly with no significant variation in the precipitate vicinity. Similar observation was made whatever the selected $\mathrm{g}_{\mathrm{i}}$ vector was. As the small phase fluctuations are in the range of the image noise contribution, we conclude that there is no significant displacement in the vicinity of the precipitates elongated in the (11-20) plane.

Regarding the monoplanar precipitate laying in the (1-100) plane, HRTEM image of isolated precipitate like Figure $5 \mathrm{a}$ has been used for the analysis of displacement in the magnesium matrix. The phase map given in Figure $5 \mathrm{~b}$ was obtained for a (1-100) selected vector. According to the profile in Figure $5 \mathrm{c}$, there is a significant phase fluctuation in the vicinity of the monoplanar precipitate. For a $(1-100)$ selected vector, the spacing is $0.27 \mathrm{~nm}$ and corresponds to a $2 \pi$ radian phase or 256 grey levels. The phase fluctuations measured on the profile (Fig $5 \mathrm{C}$ ) corresponds then to $0.03 \mathrm{~nm}$. This value can be compared to the difference in atomic radii (empirical values: $\overline{\mathrm{R}}(\overline{\mathrm{Y}}),=0.18 \mathrm{~nm} ; \overline{\mathrm{R}}(\overline{\mathrm{Nd}})$ and $\mathrm{R}(\overline{\mathrm{Mg}})=0.15 \mathrm{~nm}$, calculated values : $\mathrm{R}(\mathrm{Y})=0.21 \mathrm{~nm} ; \mathrm{R}(\mathrm{Nd})=0.2 \mathrm{~nm}$ and $\mathrm{R}(\mathrm{Mg})=0.15 \mathrm{~nm})$ [18]. It comes out that the displacement in the precipitate vicinity is in the range expected for a size effect of $\mathrm{Y}$ or $\mathrm{Nd}$ atoms in a magnesium matrix.

From the displacement field it is also possible to derive the strain field. Though having the full strain field information requires several phase maps. However, in the present case, because of the precipitate extension along the $\mathrm{Mg} \mathrm{c}$-axis, small displacement along this direction can be assumed. The precipitates being monoplanar, it can be also assumed that the displacement along the [11-20] direction is negligible in comparison with the one along the [1-100] direction. In that case, only the displacement component parallel to the [1-100] direction is significant. The $\mathrm{Mg} \mathrm{c}$-axis being taken as the $\mathrm{z}$ direction and [1-100] and [11-20]

$\mid$ as $\mathrm{x}$ and $\mathrm{y}$ directions, the phase map in Figure $5 \mathrm{~b}$-which displays $\mathrm{u}_{\mathrm{x}}(\mathrm{x}, \mathrm{y})$ - contains the essential part of the displacement field information. As a consequence of the above approximation, the strain field will essentially consist of the $\varepsilon_{\mathrm{xx}}$ and $\varepsilon_{\mathrm{xy}}$ components. Actually, the local slope on the profile in Fig 5c, which shows the variation of the displacement component along a [1-100] direction, gives the strain field component $\varepsilon_{\mathrm{xx}}$. A flat profile indicating no strain is observed away from the precipitate while in the precipitate vicinity a strain is present. This strain affects the vicinity of the precipitate over $1 \mathrm{~nm}$ on both sides of the precipitates.
Deleted: 3

Deleted: $3 b$

Deleted: $3 d$

Deleted: $3 b$

Deleted: to

Deleted: Besides, the

Deleted: This

Deleted: being

Deleted: $4 \mathrm{a}$

Formatted: Highlight

Deleted: deformation

Deleted:

Formatted: Highlight

Deleted: analysis of

Deleted: $4 \mathrm{~b}$

Deleted: $4 \mathrm{~d}$

Deleted: $4 d$

\section{Deleted: deformation}

Deleted: displacement

Deleted: $4 b$

Deleted: the displacement field

Deleted: in

Deleted: $4 d$

\subsection{Habit planes and precipitate phase precursors}


After 1324 hours ageing at $150^{\circ} \mathrm{C}$ in the $\mathrm{Mg}$-Y-Nd alloy, the HRTEM image illustrated in Figure 6 reveals two types of precipitates illustrated respectively by Figure $6 \mathrm{~b}$ and 5c. Comparison with Figures 5 shows that the precipitate in Figure $6 \mathrm{~b}$ corresponds to a regular stacking of (1-100) monoplanar $\mathrm{DO}_{19}$ ordered precipitates. In this stack, the monoplanar $\mathrm{DO}_{19}$ motives are repeated every three (1-100) $\mathrm{Mg}$ planes, and result in an orthorhombic structure, with parameters in agreement with the $\beta$ ' phase ones. This structure may be body-centred or base-centred. It is worth noting that the $3 \mathrm{Mg}$ (1-100) planes correspond to the $1 \mathrm{~nm}$ extension of deformation revealed by the image analysis reported in section 3.2. Since there are three possible (1-100) $\mathrm{DO}_{19}$ ordered precipitates in the $\mathrm{Mg}$ structure, there are then three variants for the orthorhombic phase. On the other hand, the precipitates elongated in the (11-20) plane (Fig. 6c) show a $\mathrm{DO}_{19}$ ordering. However, after some thickening, the $\mathrm{DO}_{19}$ type ordering is better defined (Fig. $\left.6 \mathrm{c}\right)$. The presence of the $\beta$, phase is confirmed by electron diffraction patterns not reported here. On the other hand, the $\mathrm{DO}_{19}$ phase could not be detected by electron diffraction since its reflection overlaps with the ones of the $\beta$ ' phase variants.

The HRTEM images suggest that, in the precipitation sequence, the precipitates with (1$100)$ or $(11-20)$ habit plane act as precursors for further $\mathrm{DO}_{19-}-\beta$ " and bco- $\beta$ ' precipitates. Though both precursors show a $\mathrm{DO}_{19}$ ordering, depending on the habit plane, the phase which further develops is either a $\mathrm{DO}_{19}$ structure or a bco structure.

\subsection{Microstructure at peak hardening}

At peak hardening for the $\mathrm{Mg}-\mathrm{Y}-\mathrm{Nd}$ alloy $\left(1896 \mathrm{~h} 150^{\circ} \mathrm{C}\right)$, the fine scale precipitation evolves into a network of precipitates. As illustrated by Figure $7 \mathrm{a}$, two types of precipitates with different morphologies and structures are identified owing to the diffraction pattern and the local FFTs. According to the streaks on the electron diffraction pattern along the $\llbracket 11-20 \rrbracket$ zone axis (not reported here), the precipitates have an approximate $10 \mathrm{~nm}$ length along the $\mathrm{Mg}$ $\mathrm{c}$ axis. There are platelets with the $\mathrm{DO}_{19}-\beta$ " structure (typical projected sizes $1.5 \mathrm{~nm}$ x $10 \mathrm{~nm}$ ) and rods with the bco- $\beta$ ' phase structure (typical projected sizes $3 \times 3 \mathrm{~nm}$ ). In the following this rod shape will be referred as globular, a term not appropriate but currently used by other | authors [15] [16]. The network is then built by $\mathrm{DO}_{19}$ platelets, which are more or less connected by $\beta$ ' precipitates showing the 3 expected orientation variants.

Regarding the Mg-Y-Gd alloys, peak hardening is obtained for $64 \mathrm{~h}$ or $128 \mathrm{~h}$ at $200^{\circ} \mathrm{C}$ depending on the Y/Gd ratio. However, in both cases, the peak microstructures are typically the ones shown in Figure $7 \mathrm{~b}$. There is only one type of precipitate which has the $\beta$ ' structure according to the HRTEM images and the local FFT. The $\beta$ ' phase precipitates also show the so-called globular morphology. In this case, the precipitates form a network only built by the 3 variants of $\beta$ ' phase precipitates, the typical sizes in the basal planes are $10 \mathrm{~nm} \times 7 \mathrm{~nm}$. As for the Mg-Y-Nd alloy, the [11-20] diffraction patterns also indicate that the size of precipitates is about $10 \mathrm{~nm}$ long along the $\mathrm{Mg}$ c-axis.

\begin{tabular}{l}
\hline Deleted: $\mathrm{a}$ \\
\hline Deleted: 1800 \\
\hline Deleted: 200 \\
\hline Deleted: 5 \\
\hline Deleted: $5 \mathrm{~b}$ \\
Deleted: 4 \\
\hline Deleted: $5 \mathrm{~b}$ \\
\hline
\end{tabular}

Deleted: $5 \mathrm{c}$

Deleted: $5 c$

Deleted: $\mathrm{p}$

\section{Deleted: $6 a$}

Deleted: (

Deleted: )

Deleted: and in previous study 


\subsection{Precipitates in the overaged states}

In overaged $\mathrm{Mg}-\mathrm{Y}-\mathrm{Nd}$ alloy, the $\mathrm{DO}_{19-} \beta$ ', phase transforms into the bco- $\beta$ ' phase. This transformation will not be detailed here since it was already reported in a previous work [16]. Besides, another phase called $\beta_{1}[15]$ (fcc structure $\mathrm{a}_{\beta 1}=0.74 \mathrm{~nm}$ ) appears and grows as large platelets $(10 \mathrm{~nm}$ x $50 \mathrm{~nm})$. This phase was clearly identified in alloys containing $\mathrm{Nd}$ mixed | with other rare earths $[15,16,17]$.The microstructure is made of two types of precipitates: small $\beta$ ' precipitates and large $\beta_{1}$ platelets [16]. In comparison with the peak hardening | microstructure, the microstructure in overaged states does not consist any more of a precipitate network.

For the Mg-Y-Gd alloy overaged $1104 \mathrm{~h}$ at $200^{\circ} \mathrm{C}$, HRTEM imaging (Fig. 8) indicates that the bco- $\beta$ ' phase is still present. In the two Mg-Y-Gd alloys, the $\beta$ ' phase is identified by diffraction and FFTs. Comparing with other ageing states, the morphology has turned from the so-called globular shape to thick platelets lying in the (11-20) plane. This change is due to preferential growth along the [1-100] direction. In both alloys, a selection of two or even only one $\beta$ ' phase variant is observed.

As illustrated by Figure $8 \mathrm{a}$, a dark contrast is observed in the vicinity of the precipitates. This diffraction contrast is due to a strong deformation field in the vicinity of precipitates. Such a feature has not been observed in the Mg-Y-Nd alloys. The combined effect of the variant selection and precipitate preferential growth contributes to a quite anisotropic microstructure compared with the peak ageing one. The precipitate sizes are typically $30 \mathrm{~nm} x$

$100 \mathrm{~nm}$ and the $\mathrm{Mg}$ domains are in the same range of size. Besides, as shown in Figure $8 \mathrm{~b}$, some nano-sized domains of $\mathrm{Mg}$ can be found within the $\beta^{\prime}$ phase particles.

\section{Discussion}

In summary, the $\beta^{\prime}$ phase precipitation is dominant in $\mathrm{Mg}-\mathrm{Y}-\mathrm{Gd}$ alloys while $\mathrm{Mg}-\mathrm{Y}-\mathrm{Nd}$ alloys displays both the $\beta$, and $\beta$ ', phases. Besides, we also show that the bco- $\beta$ ' phase structure is strongly related to the early stages of precipitation, more precisely to the existence of monoplanar (1-100) precipitate precursors with $\mathrm{DO}_{19}$ ordering while the $\mathrm{DO}_{19}-\beta$,' phase growth is rather depending on the (11-20) precursors. According to the analysis of HREM images, the formation of a (1-100) $\mathrm{DO}_{19}$ mixed layer precursor induces in its vicinity a symmetric deformation of the magnesium matrix extending on several planes. Remarkably, the precursor precipitates with a (11-20) habit plane do not show any particular displacement field in its vicinity and, under ageing, they grow as $\mathrm{DO}_{19}-\beta$ " phase precipitates. Hence, we interpret the fact that the $\mathrm{DO}_{19-} \beta$ " phase cannot form from the (1-100) monoplanar precipitates as a result of the strain field which prevents from the building of the second (1100) mixed layer necessary to form the $\mathrm{DO}_{19}$ structure.

As a confirmation of this point of view, we note that, in the $\beta$ 'phase, the second (1-100) mixed layer is formed at a distance where the deformation vanishes. Hence, the resulting $\beta$ ' phase, which has an orthorhombic structure -instead of the hexagonal $\mathrm{DO}_{19}$ structure- appears to be related to the strain field extension. The formation of the metastable $\beta$ ' phase is thus strongly dependent on elastic deformation while the $\mathrm{DO}_{19}-\beta$, phase is formed in absence of a
Deleted: consists then in

Deleted: in

\section{Deleted: 7}

Deleted: $7 \mathrm{a}$ 
strain field and then rather results from chemical ordering, Note that in such a formation scheme for the $\beta$ ' phase, a body or a base centred structure can be expected. This may explain why the $\beta$ ' phase Bravais lattice found in the literature is ill defined. Actually, depending on $\mathrm{RE}$ elements and the related strain field along the Mg c-axis, a body or a base centred structure may be built.

According to [3], the expected habit planes regarding $\mathrm{DO}_{19}$ order are both (11-20) and (1100). These planes should have a low interfacial energy as they are both showing alternate sequence of pure $\mathrm{Mg}$ and mixed Mg-RE planes. Since the presence of the $\beta$ ' phase results from the existence of (1-100) $\mathrm{DO}_{19}$ ordered layers, the comparison between the Mg-Y-Gd and the Mg-Y-Nd alloys indicates that the RE element are influencing the selection of a particular habit plane. For instance, the use of $\mathrm{Gd}$ instead of $\mathrm{Nd}$, may rather favour the (1-100) monoplanar precursors and so the formation of the bco- $\beta$ 'phase.

A direct consequence of the bco- $\beta$ 'phase formation instead of $\mathrm{DO}_{19}-\beta$ '" in $\mathrm{Mg}-\mathrm{Y}-\mathrm{Gd}$ alloy is the precipitate volume fraction. $\mathrm{A} \mathrm{DO}_{19}-\beta$ " phase has a $\mathrm{Mg}_{3} \mathrm{X}$ composition. For some alloys, the bco- $\beta$ 'phase has been analysed by TEM-EDX [9,13]: $\mathrm{Mg}_{12} \mathrm{YNd}$ and $\mathrm{Mg}_{12} \mathrm{YNd}_{2}$ compositions have been reported, which are respectively corresponding to 14 at $\%$ and 20 at $\%$ $\mathrm{RE}$ content. According to the formation scheme reported here, the $\beta$ ' phase composition would rather be $\mathrm{Mg}_{15} \mathrm{X}$, i.e. a 6.2 at\% RE content. In the Mg-Y-Nd alloys, as both bco- $\beta$, phase and $\mathrm{DO}_{19}-\beta$ " phase coexist, the precipitate volume fraction cannot be estimated from the composition. In the prepared Mg-Y-Gd alloys, the RE content being 2.2 at $\%$, since only the $\beta$ ' phase forms and assuming a negligible solute content in the matrix, the expected volume fraction of precipitate is $35 \%$. A high volume fraction is confirmed by the microstructure in the overaged states: the precipitate size is on the same order as the distance between precipitates. The volume fraction derived from the $\beta$ '-phase composition of WE alloys $[9,13]$ would rather give 11 to $16 \%$, which is too low to be consistent with the observed microstructure. Finally, the volume fraction reachable for $\mathrm{Mg}_{15} \mathrm{X} \beta$, phase precipitate is almost 4 times the one expected for $\mathrm{DO}_{19}$ precipitation.

In Mg-Y-Gd alloys, the precipitates being on a nanometer scale, the high volume fraction leads to nanostructured alloys showing nanosized $\mathrm{Mg}$ domains separated by $\beta$ ' phase precipitates forming a three-dimensional network. Regarding the network connections, the bco- $\beta$ ' phase offers 3 possible orientation variants while the $\mathrm{DO}_{19}-\beta$ " phase provides only one variant. Hence, the lower symmetry of the orthorhombic phase compared with the high symmetry hexagonal $\mathrm{DO}_{19}$ phase contributes to the formation of a more complex network. Besides this multiplication of the connection possibilities, for a constant RE content, the precipitation of bco- $\beta$ ' phase instead of the $\mathrm{DO}_{19}-\beta$ " phase strongly increases the volume fraction. A complex and fine scale microstructure results, which is appropriate for improving mechanical properties. A strong strain field is present in the $\mathrm{Mg}$ domain as revealed by the TEM images of the Mg-Y-Gd overaged states, This strain field is due to the bco- $\beta$, phase precipitates. The bco- $\beta$ ' phase formation contributes to relax the deformation along the [1100] direction whereas the deformation along the [11-20] direction is not relaxed The bco- $\beta$, precipitates are then well developed along the [1-100] direction and show a limited growth along the [11-20] direction, According to the TEM image contrast, the displacement field due to the bco- $\beta$ 'precipitates extends over almost $1 / 3$ of the $\mathrm{Mg}$ domain. This effect should also contribute to improve mechanical behaviour since the motion of dislocations in such distorted matrix will be difficult. Actually, mechanical tests carried out on the Mg-Y-Gd alloys have
Deleted: effect

Deleted: Actually, a

Deleted: range

Deleted: It comes out a

Deleted: Besides,

Deleted: , a strong strain field is present in the $\mathrm{Mg}$ domain

Deleted:

Deleted: and results in

Deleted: of precipitates in this direction as well as strain in the Mg grains

Deleted: deformation 
revealed a very high level of mechanical properties in comparison with the Mg-Y-Nd alloys. These mechanical tests detailed in [19] will be reported in a forthcoming publication.

\section{Conclusion}

We have reported a comparative study of the microstructure of two Mg-RE alloys. This work was aiming at a better understanding of the precipitation sequence in magnesium alloys containing RE elements. We have established the key role played by the earliest stages in the

| formation of either the $\mathrm{DO}_{19}-\beta$ " or the bco- $\beta$ 'phase. The earliest stages consist of monoplanar precursor precipitates showing a $\mathrm{DO}_{19}$ ordering with two possible habit planes: $(1-100)$ and | (11-20). The displacement field in the vicinity of both precipitates has been measured using appropriate analysis of the HREM images. We have shown that the $\beta$ ' phase results from an ordered stacking of the (1-100) monoplanar precipitates and that the period of this stacking is related to the extension of the deformation due to the (1-100) monoplanar precipitates. According to our observations, the (1-100) monoplanar precipitates lead to the formation of the bco- $\beta$ ' phase while the monoplanar precipitates with a (11-20) habit plane form the $\mathrm{DO}_{19}$ $\beta$ " phase. The two alloys studied here show that the composition, i. e. the RE element choice, influences the selection of one habit plane or the other. As a consequence, depending on

| composition, bco- $\beta$ ' or $\mathrm{DO}_{19}-\beta$ " phases may be favoured. Because of its low RE content, the bco- $\beta$ ' phase formation leads to a very high volume fraction of precipitates. The Mg-Y-Gd alloys, which correspond to the selection of only the bco- $\beta$ 'phase, confirm the high precipitate volume fraction that we expect from the bco- $\beta$ 'phase formation scheme as well as the high level of mechanical properties resulting from the combined effect of volume fraction and strong strain field in the Mg matrix.

\section{Acknowledgements}

The authors are grateful to P.Chaudouet, from the Laboratoire des Matériaux et du Génie Physique, Grenoble, for his help in the preparation of $\mathrm{Mg}-\mathrm{Gd}-\mathrm{Y}$ alloys.

\section{References}

[1] A.Guinier, Solid State Physics , 1959, (9), pp 293-398.

[2] J.Lendvai, Materials Science Forum, 1996, vol. 217-222, pp 43-56.

[3] I.J.Polmear, Light Alloys Metallurgy on the Light Metals, Metallurgy and Materials Science, third Edition, 1995, pp 196-247.

[4] http://www.magnesium-elektron.com/

[5] L.L.Rokhlin, N.I.Nikitina, Zeitschrift fur Metallkunde, 1994, 85(12), pp 819-23.

[6] I.A.Anyanwu, S.Kamado, Y.Kojima, Materials Transactions, 2001, 42(7), pp 1206-11.

[7] S.Kamado, Y.Kojima, S.Taniike, S.Hama, Magnesium Alloys and Their Applications, Proceedings Volume, 1998, pp 169-74.

[8] B.Smola, I.Stulikova, F. von Buch, B.L.Mordike, Materials Science and Engineering, 2002, A324, pp 113-17. 
[9] G.W.Lorimer, R.Azari-Khosroshashi, M.Ahmed, Proceedings of the International Conference on Solid-Solid State Transformations, The Japan Institute of Metals, 1999, pp 185-92

[10] G.W.Lorimer, Proceedings of the London Conference on Magnesium Technology, The Institute of London, 1986, pp 47-53.

[11] T.Sato, I.Takahashi, H.Tezuka, A.Amio, Journal of The Japan Institute of Light Metals, 1992, pp 804-09.

[12] M.Suzuki et al., Materials Science and Engineering, 1998, A252, pp 248-55.

[13] M.Ahmed, R.Pilkington, G.W.Lorimer, Magnesium Alloys and Their Applications, Proceedings Volume, 1992, pp 251-57.

[14] M.J.Hytch, E.Snoeck, R.Kilaas, Ultramicroscopy, 1998, vol.74, pp 131.

[15] J.F.Nie, B.C.Muddle, Acta Materialia, 2000, 40(10), pp 1691-1703

[116] C.Antion, P.Donnadieu, F.Perrard, A.Deschamps, C.Tassin, A.Pisch, Acta Materialia, 2003, 51, pp 5335-48.

[17] P.J.Apps, H.Karimzadeh, J.F.King, G.W.Lorimer, Scripta Materialia, 2003, 48, pp 475-81.

[18] www.webelements.com

[19] C. Antion, Etude du système Mg-Mn-Y-Gd et développement d'alliages de magnésium pour des applications structurales à chaud, $\mathrm{PhD}$ thesis, Institut National Polytechnique de Grenoble (2003)

\section{Figure Captions}

Figure 1 : Hardness tests carried out on the $\mathrm{Mg}-\mathrm{Y}-\mathrm{Nd}$ and $\mathrm{Mg}-\mathrm{Y}-\mathrm{Gd}$ alloys. These tests allow to determine the underaging, peak aging, and overaging treatments studied here. Figure 1a : Hardness tests for the Mg-Y-Nd alloy

Figure 1b : Hardness tests for the two Mg-Y-Gd alloys. The label 8Gd3Y refers to the composition : Mg-1 wt\% Mn- 3 wt\% Y- 8 wt\% Gd ; the label 4Gd5Y to the composition Mg$1 \mathrm{wt} \% \mathrm{Mn}-5 \mathrm{wt} \%$ Y- 4 wt $\%$ Gd.

Figure 2 : Microstructure of the Mg-Y-Gd alloy after $4 \mathrm{~h}$ ageing at $200^{\circ} \mathrm{C}$

Figure 2a : Diffraction pattern along the [0001] zone axis. Very weak diffuse intensity can be detected at half distance of the intense $\mathrm{Mg}$ reflections as expected for a $\mathrm{DO}_{19}$ ordering.

Figure 2b : HRTEM image taken along the [0001] zone axis showing some local intensity fluctuation.

Figure 2c : Fast Fourier Transform (FFT) of Figure 2b showing some very diffuse intensity. The ring indicates the mask location used for numerical dark field (DF) by inverse FFT.

Figure 2d : Numerical DF pointing out higher intensity regions on the scale similar to the $\mathrm{DO}_{19}$ cell size. 


\section{Figure 3 : Microstructure of the Mg-Y-Nd alloy after $864 \mathrm{~h}$ ageing at $150^{\circ} \mathrm{C}$}

Figure 3a : Diffraction pattern along the [0001] zone axis . Diffuse streaks are now clearly visible, the streak positions are consistent with a $\mathrm{DO}_{19}$ ordering.

Figure 3b : Diffraction pattern along the [11-20] zone axis. The diffuse streak width along the $\mathrm{Mg}-\mathrm{c}$ axis (direction indicated by the arrow) gives the inverse of the precipitate length. Figure 3c: HRTEM image taken along the [0001] zone axis showing local organisation. Figure 3d : Numerical DF (obtained with a mask similar as in figure 2c) showing two types of very fine precipitates laying in (01-10) and (11-20) planes.

\section{Figure 4 : Deformation in the vicinity of the (11-20) $\beta$ ' type precipitate}

Figure 4a : HRTEM image of one precipitate laying in the (11-20) plane (Mg-Y-Nd alloy aged $864 \mathrm{~h}$ at $150^{\circ} \mathrm{C}$ ).

Figure $4 \mathbf{b}$ : Phase image obtained by selection of the (11-20) reflection as indexed in the FFT in Figure 4c.

Figure 4d : Profile of the phase image along the line AB marked in Figure 4b. The horizontal scale corresponds to direct distance, here $\mathrm{AB}=7 \mathrm{~nm}$, the vertical scale reads the displacement of the (11-20) planes along the [11-20] direction. The 256 grey level corresponds to $\mathrm{d}_{(11-20)}=$ $0.16 \mathrm{~nm}$, the phase fluctuations in Figure $4 \mathrm{~d}$ indicate $\pm 0.003 \mathrm{~nm}$ displacement, which is too small to be significant.

\section{Figure 5 : Deformation in the vicinity of the (1-100) type precipitate}

Figure 5a : HRTEM of a monoplanar precipitate laying in the (1-100) plane (Mg-Y-Nd alloy aged $864 \mathrm{~h}$ at $150^{\circ} \mathrm{C}$ ).

Figure 5b : Phase image obtained by selection of the (1-100) reflection as indexed in the FFT in Figure 4c.

Figure 5c : Profile of the phase image along the line $A B$ marked in Figure $5 b$. On Figure $5 c$, $\mathrm{AB}=7 \mathrm{~nm}$, the vertical scale reads the displacement of the (1-100) planes along the [1-100] direction. Note that the location of deformation on both side of the precipitate is over a $1 \mathrm{~nm}$ range. The 256 grey level corresponding to $\mathrm{d}_{(1-100)}=0.27 \mathrm{~nm}$, the displacement is $0.03 \mathrm{~nm}$ on a $1 \mathrm{~nm}$ range.

Figure 6 : Formation of $\mathrm{DO}_{19-} \beta$ "' and $\beta$ ' precipitates in Mg-Y-Nd alloy aged 1324 hours at $150{ }^{\circ} \mathrm{C}$.

Figure 6a : The HRTEM image shows two types of precipitates respectively lying in (11-20) and $(0-110)$ types planes.

Figure $6 \mathbf{b}$ : The precipitate laying in the (0-110) plane are formed by a regular stacking of monoplanar precipitates as sketched in Figure 6d. 
Figure 6c : The precipitate laying in the (11-20) plane shows a $\mathrm{DO}_{19}$ type structure as sketched in Figure 6e.

\section{Figure 7 : Precipitation microstructure in the peak hardening conditions}

Figure 7a : In the Mg-Y-Nd alloy aged for $1896 \mathrm{~h}$ at $150^{\circ} \mathrm{C}$, the HRTEM image indicates two types of precipitates with different morphologies and structures $\left(\mathrm{DO}_{19}\right.$ and $\beta$ ') according to the FFTs shown in the inserts.

Figure 7b, 7c: In the Mg-Y-Gd alloy aged for $64 \mathrm{~h}$ or $128 \mathrm{~h}$ at $200^{\circ} \mathrm{C}$, the HRTEM image shows a network of only bco- $\beta$ ' phase precipitates. Three variants (labels 1, 2 and 3 on Fig. 7b) are observed.

Fig. 7c : Zoom on the HRTEM image of the connection between 2 bco- $\beta$ ' phase variants.

\section{Figure 8: $\quad$ Precipitation microstructure in overaged Mg-Y-Gd alloys}

Figure 8a : In Mg-Y-Gd alloy overaged during $1104 \mathrm{~h}$ at $200^{\circ} \mathrm{C}$, the precipitates form a connected network involving here only two variants. Note the strong diffraction contrast in the $\mathrm{Mg}$ matrix.

Figure 8b: The HRTEM image indicates that the precipitates have the $\beta$ ' phase structure. Note that very small $\mathrm{Mg}$ domains are found embedded in the $\beta$ 'phase. 

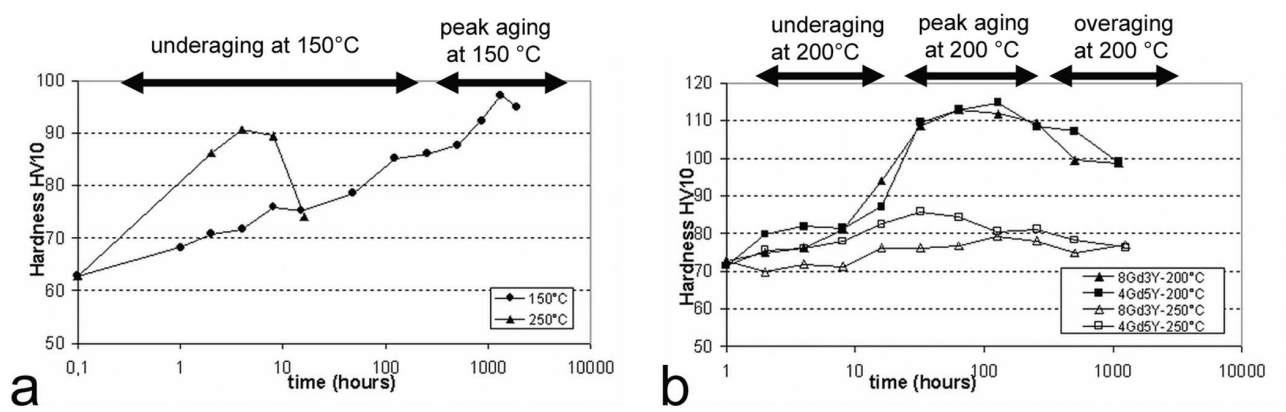

Figure 1 : Hardness tests carried out on the Mg-Y-Nd and Mg-Y-Gd alloys. These tests allow to determine the underaging, peak aging, and overaging treatments studied here.

Figure 1a : Hardness tests for the Mg-Y-Nd alloy

Figure 1b: Hardness tests for the two Mg-Y-Gd alloys. The label 8Gd3Y refers to the composition : Mg-1 wt\% Mn- 3 wt\% Y- 8 wt\% Gd ; the label 4Gd5Y to the composition Mg- 1 wt $\%$ Mn- 5 wt\% Y4 wt\% Gd.

$180 \times 62 \mathrm{~mm}(300 \times 300$ DPI $)$ 

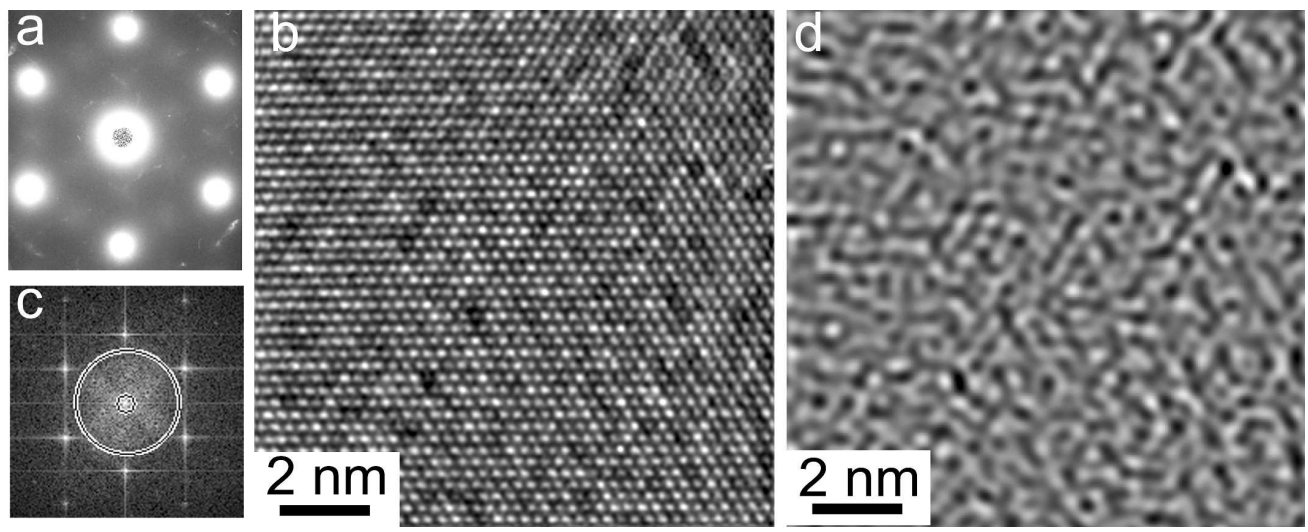

Figure 2 : Microstructure of the $\mathrm{Mg}-\mathrm{Y}-\mathrm{Gd}$ alloy after $4 \mathrm{~h}$ ageing at $200^{\circ} \mathrm{C}$

Figure 2a : Diffraction pattern along the [0001] zone axis. Very weak diffuse intensity can be detected at half distance of the intense $\mathrm{Mg}$ reflections as expected for a DO19 ordering.

Figure 2b : HRTEM image taken along the [0001] zone axis showing some local intensity fluctuation.

Figure 2c : Fast Fourier Transform (FFT) of Figure 2b showing some very diffuse intensity. The ring indicates the mask location used for numerical dark field (DF) by inverse FFT.

Figure 2d : Numerical DF pointing out higher intensity regions on the scale similar to the DO19 cell size.

$180 \times 71 \mathrm{~mm}(600 \times 600 \mathrm{DPI})$ 

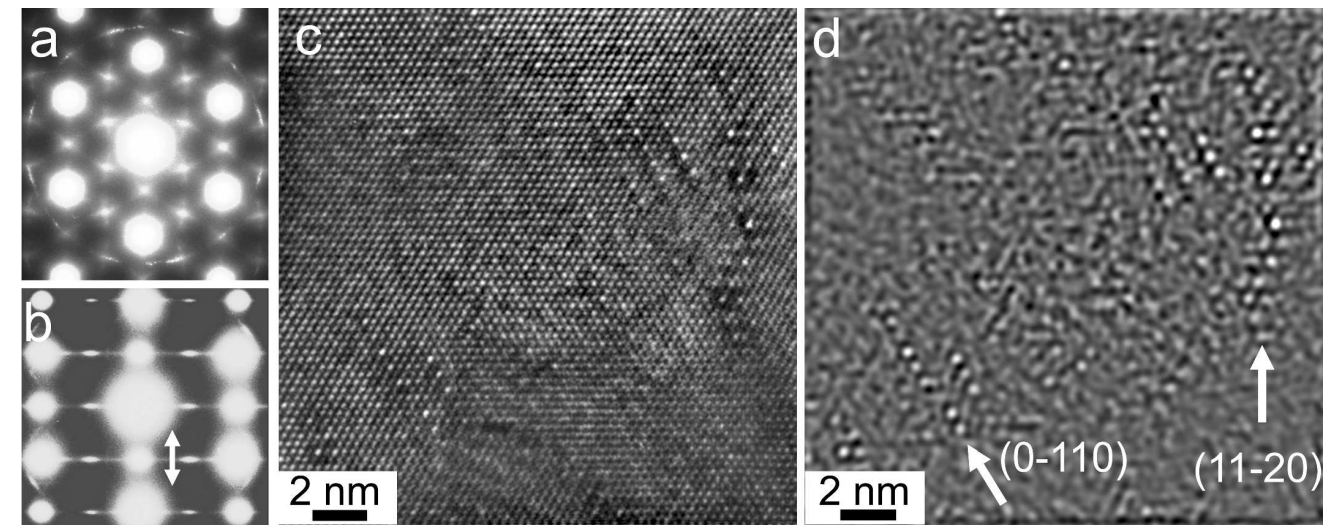

Figure 3 : Microstructure of the Mg-Y-Nd alloy after $864 \mathrm{~h}$ ageing at $150^{\circ} \mathrm{C}$

Figure 3a : Diffraction pattern along the [0001] zone axis. Diffuse streaks are now clearly visible, the streak positions are consistent with a DO19 ordering.

Figure 3b : Diffraction pattern along the [11-20] zone axis. The diffuse streak width along the Mg-c axis (direction indicated by the arrow) gives the inverse of the precipitate length.

Figure 3c: HRTEM image taken along the [0001] zone axis showing local organisation.

Figure 3d : Numerical DF (obtained with a mask similar as in figure $2 c$ ) showing two types of very fine precipitates laying in (01-10) and (11-20) planes.

$$
180 \times 71 \mathrm{~mm}(600 \times 600 \mathrm{DPI})
$$



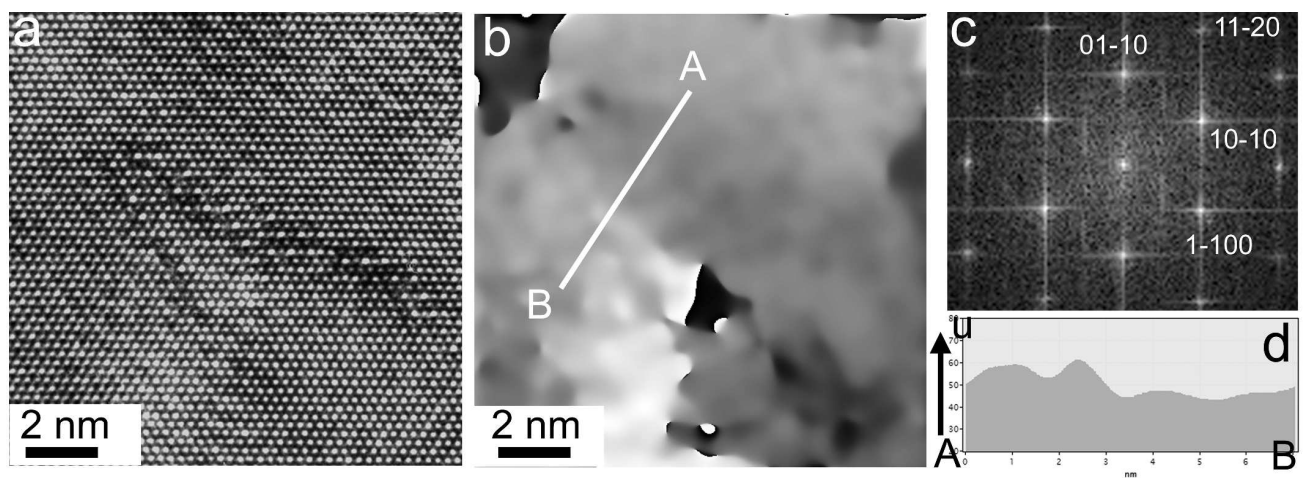

Figure 4 : Deformation in the vicinity of the (11-20) $B^{\prime}$ type precipitate

Figure 4a : HRTEM image of one precipitate laying in the (11-20) plane (Mg-Y-Nd alloy aged $864 \mathrm{~h}$ at $\left.150^{\circ} \mathrm{C}\right)$.

Figure $4 \mathrm{~b}$ : Phase image obtained by selection of the (11-20) reflection as indexed in the FFT in Figure 4c.

Figure $4 \mathrm{~d}$ : Profile of the phase image along the line $A B$ marked in Figure $4 \mathrm{~b}$. The horizontal scale corresponds to direct distance, here $A B=7 \mathrm{~nm}$, the vertical scale reads the displacement of the (11-20) planes along the [11-20] direction. The 256 grey level corresponds to $d(11-20)=0.16 \mathrm{~nm}$, the phase fluctuations in Figure $4 \mathrm{~d}$ indicate $\pm 0.003 \mathrm{~nm}$ displacement, which is too small to be significant. 

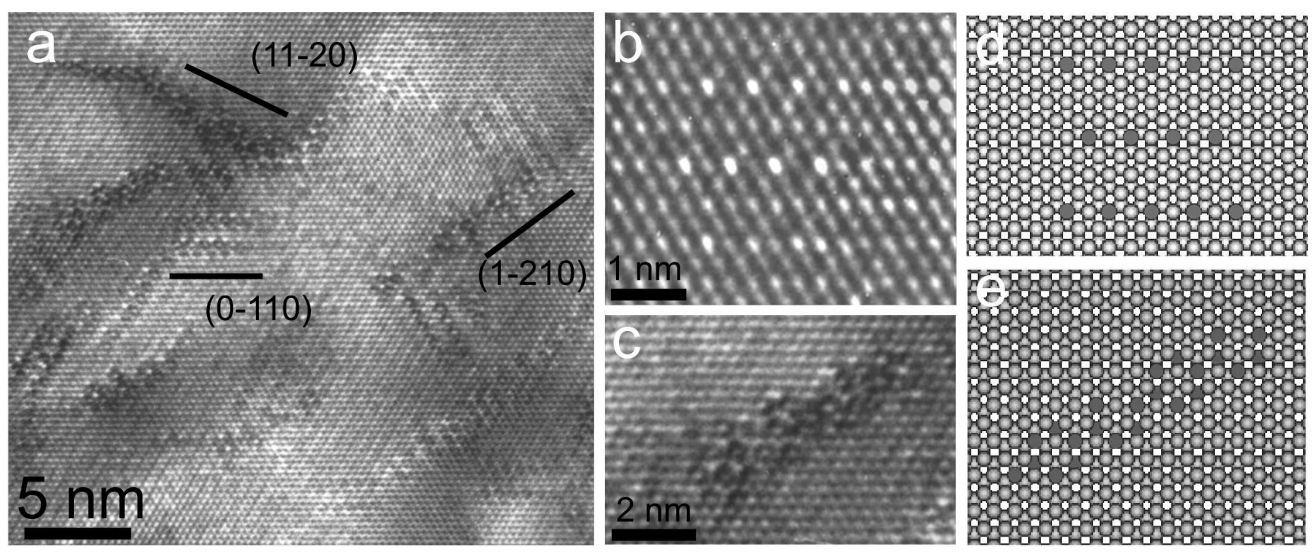

Figure 6 : Formation of DO19- $\beta^{\prime \prime}$ and $B^{\prime}$ precipitates in Mg-Y-Nd alloy aged 1324 hours at $150{ }^{\circ} \mathrm{C}$.

Figure 6a: The HRTEM image shows two types of precipitates respectively lying in (11-20) and (0110) types planes.

Figure $6 \mathrm{~b}$ : The precipitate laying in the $(0-110)$ plane are formed by a regular stacking of monoplanar precipitates as sketched in Figure 6d.

Figure $6 \mathrm{c}$ : The precipitate laying in the (11-20) plane shows a DO19 type structure as sketched in Figure $6 e$.

$180 \times 73 \mathrm{~mm}(600 \times 600 \mathrm{DPI})$ 

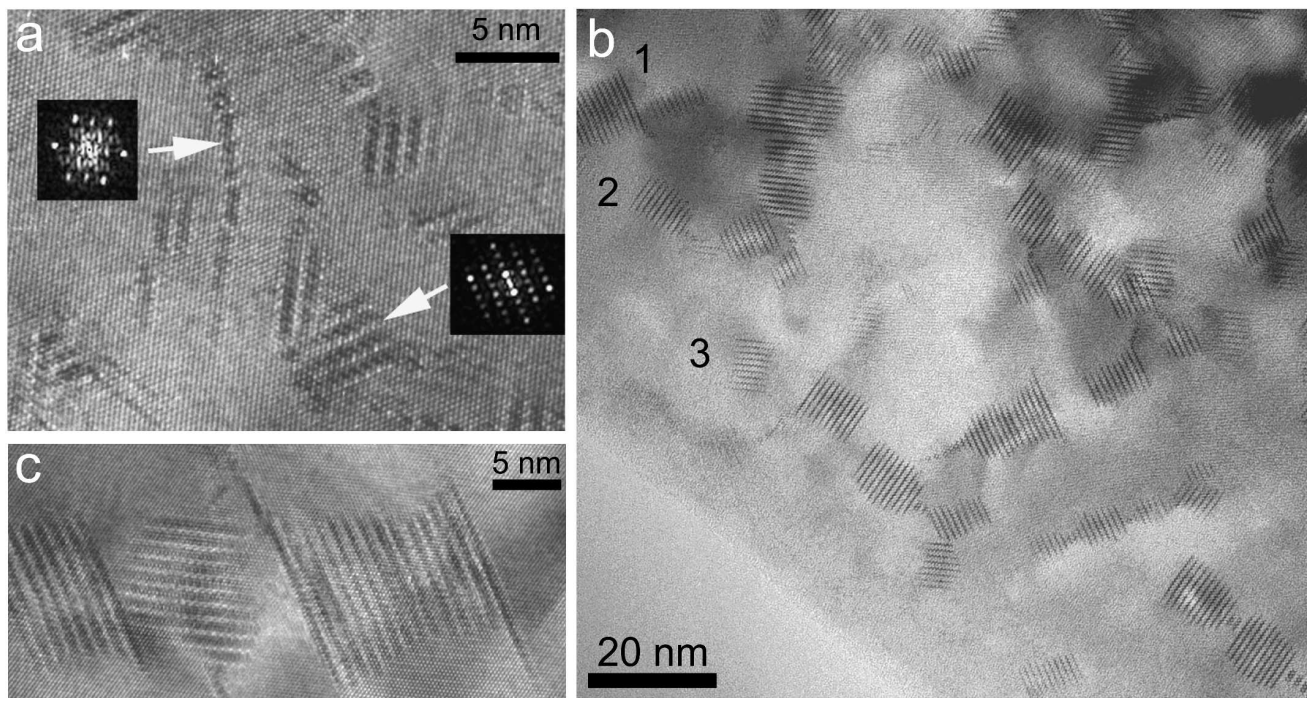

Figure 7 : Precipitation microstructure in the peak hardening conditions

Figure $7 \mathrm{a}:$ In the $\mathrm{Mg}-\mathrm{Y}-\mathrm{Nd}$ alloy aged for $1896 \mathrm{~h}$ at $150^{\circ} \mathrm{C}$, the HRTEM image indicates two types of precipitates with different morphologies and structures (DO19 and $B^{\prime}$ ) according to the FFTs shown in the inserts.

Figure 7b, 7c: In the Mg-Y-Gd alloy aged for $64 \mathrm{~h}$ or $128 \mathrm{~h}$ at $200^{\circ} \mathrm{C}$, the HRTEM image shows a network of only bco- $\beta^{\prime}$ phase precipitates. Three variants (labels 1, 2 and 3 on Fig. 7b) are observed.

Fig. 7c : Zoom on the HRTEM image of the connection between 2 bco- $\beta^{\prime}$ phase variants.

$$
180 \times 95 \mathrm{~mm}(600 \times 600 \mathrm{DPI})
$$



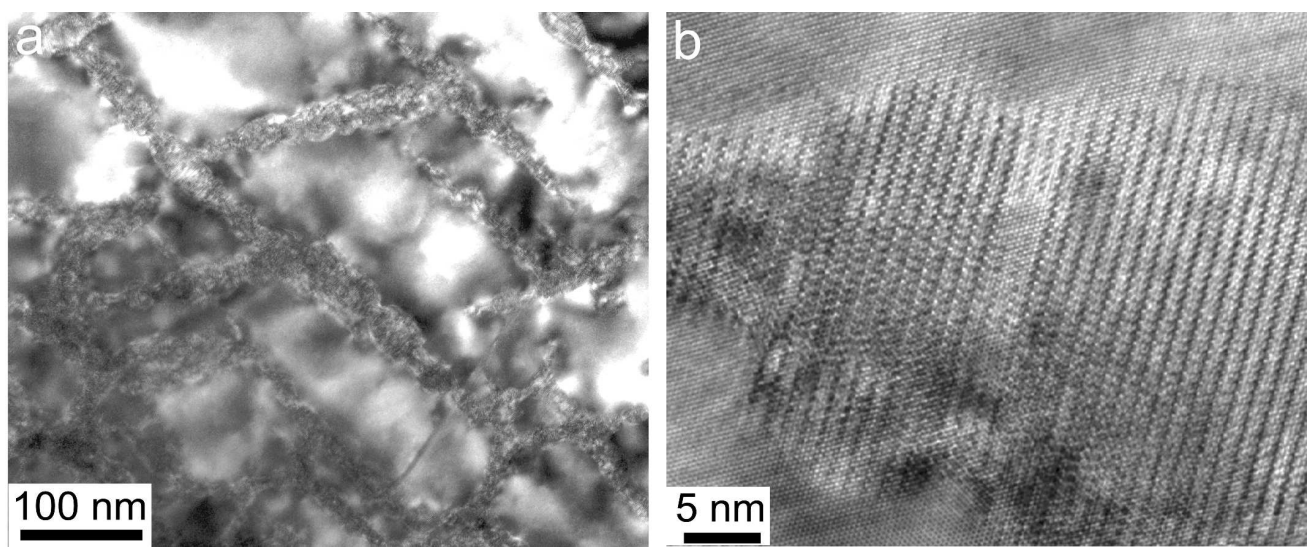

Figure 8 : Precipitation microstructure in overaged Mg-Y-Gd alloys

Figure 8a : In Mg-Y-Gd alloy overaged during $1104 \mathrm{~h}$ at $200^{\circ} \mathrm{C}$, the precipitates form a connected network involving here only two variants. Note the strong diffraction contrast in the Mg matrix. Figure 8b: The HRTEM image indicates that the precipitates have the $\beta^{\prime}$ phase structure. Note that very small $\mathrm{Mg}$ domains are found embedded in the $B^{\prime}$ phase.

$180 \times 74 \mathrm{~mm}(600 \times 600 \mathrm{DPI})$ 